\title{
Intra-uterine and Genetic Influences on the Relationship Between Size at Birth and Height in Later Life: Analysis in Twins
}

\author{
Richard G. IJzerman',2, Coen D.A. Stehouwer', Mirjam M. van Weissenbruch², Eco J. de Geus ${ }^{3}$, \\ Dorret I. Boomsma ${ }^{3}$ \\ 'Department of Internal Medicine, Institute for Cardiovascular Research-Vrije Universiteit, Academic Hospital Vrije Universiteit, Amsterdam, \\ The Netherlands \\ ${ }^{2}$ Department of Paediatrics, Institute for Endocrinology, Reproduction and Metabolism, Academic Hospital Vrije Universiteit, Amsterdam, \\ The Netherlands \\ ${ }^{3}$ Department of Biological Psychology, Vrije Universiteit, Amsterdam, The Netherlands
}

\begin{abstract}
Epidemiological studies have consistently shown a positive Eassociation between size at birth (i.e. birth weight or birth length) and height in children, adolescents and adults. To examine whether this association is explained by genetic or nongenetic (intra-uterine) factors, we investigated birth weight, birth length and height in 60 dizygotic and 68 monozygotic adolescent twin pairs still living with their parents. Birth weight of the twins was obtained from their mothers. Height was measured in a standardised way. The mean age was $17 \pm 1.7$ years for the dizygotic twins and $16 \pm 1.8$ years for the monozygotic twins. Both dizygotic and monozygotic twins with the lowest birth weight from each pair had a height that was lower compared to their co-twins with the highest birth weight (dizygotic twins: $172.2 \pm 7.9$ vs. $173.8 \pm 9.4 \mathrm{~cm}[p=0.05]$; monozygotic twins: $171.1 \pm 9.4$ vs. $171.8 \pm 9.5 \mathrm{~cm}[p=0.01])$. Similarly, both dizygotic and monozygotic twins with the shortest birth length from each pair had a height that was lower compared to their co-twins with the longest birth length (dizygotic twins: $172.3 \pm 7.9$ vs. $174.9 \pm 9.7 \mathrm{~cm}[p<0.05]$; monozygotic twins: $168.9 \pm 10.6$ vs. $169.9 \pm 10.2 \mathrm{~cm}[p<0.01])$. In addition, intra-pair differences in birth weight and birth length were significantly associated with differences in height in both dizygotic twins (regression coefficient: $4.3 \mathrm{~cm} / \mathrm{kg}$ [95\% confidence interval: 1.0 to 7.5$]$ and $0.96 \mathrm{~cm} / \mathrm{cm}$ [0.17 to 1.74$]$, respectively) and monozygotic twins $(2.8 \mathrm{~cm} / \mathrm{kg}[1.4$ to 4.1$]$ and $0.73 \mathrm{~cm} / \mathrm{cm}[0.40$ to 1.06$]$, respectively). These associations were stronger in dizygotic than in monozygotic twins, but this difference was not statistically significant (for birth weight $p=0.4$; and for birth length $p=0.6)$. However, genetic model fitting indicated that models incorporating a genetic source of the covariance gave a better description of the observed association of birth weight and length with height in later life than models not incorporating this genetic source. The results were similar for data on adult height after 12 years of follow-up in a subgroup of these twin pairs. These data suggest that the association between size at birth and height in later life is influenced by non-genetic intra-uterine and by genetic factors.
\end{abstract}

Infants with a small size at birth are at increased risk of impaired postnatal growth and development (Barker, 1998). Although most affected infants show some degree of catchup in growth during the first years of life (AlbertssonWikland et al., 1993; Karlberg \& Albertsson-Wikland, 1995), epidemiological studies have consistently shown a positive association between size at birth (i.e. birth weight or birth length) and height in children (Albertsson-Wikland et al., 1993; Bavdekar et al., 1999; Hadders-Algra \& Touwen, 1990), adolescents (Bacallao et al., 1996; Ibanez et al., 2000; Paz et al., 1993; Rantakallio \& von Wendt L., 1985; Westwood et al., 1983) and adults ( Karlberg \& AlbertssonWikland, 1995; Karlberg \& Luo, 2000; Leger et al., 1997; Leger et al., 1998; Nielen et al., 1984; Sorensen et al., 1999). A recent study of approximately 40,000 young men showed that there was a mean difference of more than $7 \mathrm{~cm}$ in height between men with a low and a high birth weight $(<2500$ and $>4500 \mathrm{~g}$, respectively), and a mean difference of almost 10 $\mathrm{cm}$ in height between men who were short and those who were long at birth $(<48$ and $>55 \mathrm{~cm}$, respectively; Tuvemo et al., 1999). One leading theory postulates that intra-uterine programming in response to fetal malnutrition induces permanent changes in structure and function, which may cause shorter height in later life (Barker et al., 1998). This theory is supported by a study in East Java that showed that energy supplementation during pregnancy promoted postnatal growth in children (Kusin et al., 1992). However, human exposure to famine in utero during World War II did not result in a decreased height in later life (Ravelli et al., 1998; Stanner et al., 1997). Alternatively, it has been put forward that some factors other than intra-uterine nutrition may influence both growth in utero and during childhood. Environmental causes, particularly those associated with socio-economic status (Delpeuch et al., 2000; Sorensen et al., 1999), as well as genetic factors have been proposed (Karlberg \& Albertsson-Wikland, 1995; Paz et al., 1993; Sorensen et al., 1999). In other words, the socio-economic status or genotype responsible for short stature in later life may also cause retarded fetal growth in utero.

Address for correspondence: Prof Dr Coen DA Stehouwer, Department of Medicine, Academic Hospital Vrije Universiteit, De Boelelaan 1117, PO Box 7057, 1007 MB Amsterdam, he Netherlands.E-mail: cda.stehouwer@azvu.nl 
Twin pairs still living with their parents offer a unique opportunity to distinguish between intra-uterine, socio-economic and genetic influences (Phillips, 1993). Specifically, studying dizygotic twin pairs avoids socio-economic factors that could confound the association between size at birth and height in later life. Furthermore, investigating monozygotic (genetically identical) twin pairs allows almost complete elimination of the influence of genotype on the association between the variance in size at birth and that in height (Phillips, 1993). Therefore, if socio-economic factors are responsible for the association between size at birth and height in later life, it could be expected that the dizygotic twins with the smallest size at birth from each pair will not have a shorter height in later life compared to their co-twins with the largest size at birth. In addition, it could be expected that intra-pair differences in size at birth are not associated with intra-pair differences in height in dizygotic twins. If, however, genetic factors are responsible, these intra-pair associations would hold true for dizygotic twins, but not for monozygotic twins. To examine these issues, we investigated birth weight, birth length and height in a group of adolescent dizygotic and monozygotic twin pairs still living with their parents. To investigate whether these associations persisted into adulthood, we also analysed follow-up data on adult height in a subgroup of these twin pairs.

\section{Material and Method}

This study is part of a larger project in which cardiovascular risk factors were studied in 160 adolescent twin pairs and their parents (Boomsma et al., 1998; Boomsma, Hennis, et al., 1993; Boomsma, Kaptein, et al., 1993; Ijzerman et al., 2000). Zygosity was determined as described in detail previously (Boomsma et al., 1998). The maternal questionnaire included questions regarding birth weight, birth length and gestational age of their children (Ijzerman et al., 2000). Height was measured in a standardised way in all subjects.

In the total group, linear regression analysis was used to investigate the influence of birth weight and birth length on height in later life after adjustment for age and sex. Opposite-sex dizygotic twin pairs were excluded because of the effects of sex differences within a pair on both size at birth and height in later life. Birth weight data were available in 60 dizygotic and 68 monozygotic twin pairs, whereas birth length was available in 50 dizygotic and 61 monozygotic twin pairs. An interaction analysis was performed to investigate whether zygosity influenced the associations between size at birth and height. As in previous twin studies investigating the association between birth weight and adult health (Cheung et al., 2000; Ijzerman et al., 2000; Poulsen et al., 1997; Poulter et al., 1999; Treloar et al., 2000), we compared the twins with the lowest birth weight from each pair with their co-twins with the highest birth weight. For this analysis, the paired Student $t$ test was used and 2 dizygotic and 2 monozygotic twin pairs had to be excluded because the birth weight of the twins within a pair was equal. In addition, twins with the shortest birth length from each pair were compared with their co-twins with the longest birth length. For this analysis, 10 dizygotic and 19 monozygotic twin pairs had to be excluded because the birth length of the twins within a pair was equal. The differences in dizy- gotic twins and the differences in monozygotic twins were compared using the independent samples $t$ test, and MANOVA was used to adjust for differences in birth weight. Linear regression analysis was used to analyse whether intra-pair differences in birth weight and length influenced intra-pair differences in height in dizygotic and monozygotic twins. Intra-pair differences in size at birth were calculated by randomly subtracting the twin with the smallest size at birth from the co-twin with the largest size at birth or vice versa (Bring \& Wernroth, 1999). Interaction analysis was performed to investigate whether zygosity or sex influenced the associations between intra-pair differences in size at birth and differences in height.

To investigate whether these associations persisted into adulthood, we also analysed data on adult height after 12 years of follow-up. Data on adult height could be obtained in 31 dizygotic and 30 monozygotic twin pairs. Of these twin pairs, birth length was available in 26 dizygotic and 25 monozygotic twin pairs. In the total group, linear regression analysis was used to investigate the influence of birth weight and birth length on height in later life after adjustment for age and sex. In addition, linear regression analysis was used to analyse whether intra-pair differences in birth weight and length influenced intra-pair differences in height in dizygotic and monozygotic twins. A two-tailed $p$-value $<0.05$ was considered significant. The above analyses were performed on a personal computer using the statistical software package SPSS version 9.0 (SPSS, Chicago, IL, USA).

Finally, we used genetic model fitting to determine the relative magnitudes of genetic, common environmental and unique environmental influences on the relationship between size at birth and height in later life. Genetic model fitting uses maximum likelihood-based path analysis. Genetic model fitting was done with $\mathrm{Mx}$, a computer program specifically designed for the analysis of genetically informative data (Neale, 1995). Although less transparent than regression analyses, it is very sensitive in determining genetic and environmental influences. In addition, genetic model fitting allows the inclusion of the data of opposite-sex dizygotic twins (28 pairs). The covariance of birth weight and length with height was decomposed into a genetic and a non-genetic part. Estimates of the relative importance of these genetic and non-genetic influences were allowed to differ between men and women.

\section{$\overline{\text { Results }}$}

In the total group of twins, positive associations of birth weight and birth length with height were found after adjustment for age and sex (see Table 1). Interaction analysis indicated that these associations were not significantly modified by sex or zygosity (data not shown).

\section{Comparison Between Twins With the Smallest Size at Birth and Their Co-Twins With the Largest Size at Birth}

The differences in birth weight between the twins with the lowest birth weight and their co-twins with the highest birth weight were larger for dizygotic compared to monozygotic twin pairs (378 g and $283 \mathrm{~g}$, respectively; $p$ for the difference, 0.07 ; see Table 2). The mean age was $17.4 \pm 1.9$ years for the dizygotic twins and $16.4 \pm 2.0$ years for the 


\section{Table 1}

Association of Birth Weight and Length with Height $(\mathrm{cm})$ in the Total Group of Twins after Adjustment for Age and Sex

\begin{tabular}{lccc}
\hline Variable & Beta & $95 \%-C l$ & $P$ \\
\hline Birth weight (per kg) & 3.6 & 1.9 to 5.4 & $<0.001$ \\
Birth length (per cm) & 0.92 & 0.62 to 1.22 & $<0.001$ \\
\hline
\end{tabular}

Note: Beta is the slope of the linear regression line. $\mathrm{Cl}$ indicates confidence interval

monozygotic twins. Both dizygotic and monozygotic cotwins with the lowest birth weight from each pair were shorter in later life than their co-twins with the highest birth weight. The differences in height between the twins with the lowest and the co-twins with the highest birth weight were larger in dizygotic than in monozygotic twins, but this difference was not statistically significant ( $p$ for the difference, 0.3 ; after adjustment for differences in birth weight, $p=0.4$ ).

The differences in birth length between the twins with the shortest birth length and their co-twins with the longest birth length were larger for dizygotic compared to monozygotic twin pairs $(2.3 \mathrm{~cm}$ and $1.5 \mathrm{~cm}$, respectively; $p$ for the difference, $<0.05$, see Table 3$)$. The mean age was $17.1 \pm 1.9$ years for the dizygotic twins and $16.0 \pm 2.0$ years for the monozygotic twins. Both dizygotic and monozygotic twins with the shortest birth length from each pair were significantly shorter in later life than their co-twins with the longest birth length. The differences in height between the twins with the shortest and the co-twins with the longest birth length were larger in dizygotic than in monozygotic twins, but this difference was not statistically significant ( $p$ for the difference, 0.2; after adjustment for differences in birth length, $p=0.3$ ).

\section{Associations Between Intra-pair Differences in Size at Birth and Differences in Height}

Table 4 shows that intra-pair differences in birth weight and length were positively associated with differences in height in both dizygotic and monozygotic twins. For example, a positive difference in birth weight of $1 \mathrm{~kg}$ within pairs was associated with a positive difference in height of $4.3 \mathrm{~cm}$ in dizygotic twin pairs and $2.6 \mathrm{~cm}$ in monozygotic twin pairs. These associations were stronger in dizygotic than in monozygotic twins. But this difference was not statistically significant (for birth weight $p=0.4$; and for birth length $p=0.6$ ).

If subjects with a gestational age shorter than 37 weeks (for the analysis with birth weight, 24 dizygotic and 28 monozygotic twin pairs; for the analysis with birth length, 20 dizygotic and 25 monozygotic twin pairs) were excluded, the results were similar. Adjustment for gestational age also did not importantly change the results (data not shown). Interaction analysis indicated that the intra-pair association between size at birth and height in later life was not influenced by sex in either dizygotic or monozygotic twins.

\section{Associations Between Size at Birth and Height During Follow-up}

Birth weight and birth length were significantly associated with adult height at follow-up after adjustment for age and sex (regression coefficient: $3.7 \mathrm{~cm} / \mathrm{kg}$ [95\%-confidence interval: 1.35 to 6.1$]$ and $0.71 \mathrm{~cm} / \mathrm{cm}[0.28$ to 1.15$]$, respectively). In addition, intra-pair differences in birth

Table 2

Dizygotic and Monozygotic Co-twins According to Birth Weight

\begin{tabular}{lcccccc}
\hline & \multicolumn{2}{c}{$\begin{array}{c}\text { Dizygotic twin pairs } \\
\text { co-twin with } \\
\text { the lowest } \\
\text { birth weight }\end{array}$} & $\begin{array}{c}\text { co-twin with } \\
\text { the highest } \\
\text { birth weight }\end{array}$ & $P$ & \multicolumn{3}{c}{ Monozygotic twin pairs } \\
Variable & $2.27 \pm 0.49$ & $2.65 \pm 0.55$ & $<0.001$ & $\begin{array}{c}\text { co-twin with } \\
\text { the lowest } \\
\text { birth weight }\end{array}$ & $\begin{array}{c}\text { co-twin with } \\
\text { the highest } \\
\text { birth weight }\end{array}$ & $P$ \\
\hline Birth weight $(\mathrm{kg})$ & $58(30 / 28)$ & $58(30 / 28)$ & - & $2.34 \pm 0.51$ & $2.62 \pm 0.47$ & $<0.001$ \\
$\mathrm{~N}$ (male/female) & $17.4 \pm 1.9$ & $17.4 \pm 1.9$ & - & $66(32 / 34)$ & $66(32 / 34)$ & - \\
Age (years) & $172.2 \pm 7.9$ & $173.8 \pm 9.4$ & 0.05 & $16.4 \pm 2.0$ & $16.4 \pm 2.0$ & - \\
Current height $(\mathrm{cm})$ & & & & $171.1 \pm 9.4$ & $171.8 \pm 9.5$ & 0.01 \\
\hline
\end{tabular}

\section{Table 3}

Dizygotic and Monozygotic Co-twins According to Birth Length

\begin{tabular}{|c|c|c|c|c|c|c|}
\hline \multirow[b]{2}{*}{ Variable } & \multicolumn{2}{|c|}{ Dizygotic twin pairs } & \multirow[b]{2}{*}{$P$} & \multicolumn{2}{|c|}{ Monozygotic twin pairs } & \multirow[b]{2}{*}{$P$} \\
\hline & $\begin{array}{l}\text { co-twin with } \\
\text { the shortest } \\
\text { birth length }\end{array}$ & $\begin{array}{l}\text { co-twin with } \\
\text { the longest } \\
\text { birth length }\end{array}$ & & $\begin{array}{l}\text { co-twin with } \\
\text { the shortest } \\
\text { birth length }\end{array}$ & $\begin{array}{l}\text { co-twin with } \\
\text { the longes } \\
\text { birth length }\end{array}$ & \\
\hline Birth length $(\mathrm{cm})$ & $45.9 \pm 3.3$ & $48.2 \pm 3.2$ & $<0.001$ & $45.8 \pm 3.2$ & $47.3 \pm 3.1$ & $<0.001$ \\
\hline $\mathrm{N}$ (male/female) & $40(24 / 16)$ & $40(24 / 16)$ & - & $42(19 / 23)$ & $42(19 / 23)$ & - \\
\hline Age (years) & $17.1 \pm 1.9$ & $17.1 \pm 1.9$ & - & $16.0 \pm 1.9$ & $16.0 \pm 1.9$ & - \\
\hline Height (cm) & $172.3 \pm 7.9$ & $174.9 \pm 9.7$ & $<0.05$ & $168.9 \pm 10.6$ & $169.9 \pm 10.2$ & $<0.01$ \\
\hline
\end{tabular}


Table 4

Associations of Intra-pair Differences in Birth Weight and Length with Differences in Height $(\mathrm{cm})$

\begin{tabular}{|c|c|c|c|c|c|c|}
\hline \multirow[b]{2}{*}{ Variable } & \multicolumn{3}{|c|}{ Dizygotic twin pairs } & \multicolumn{3}{|c|}{ Monozygotic twin pairs } \\
\hline & Beta & $95 \%-\mathrm{Cl}$ & $P$ & Beta & $95 \%-\mathrm{Cl}$ & $P$ \\
\hline Birth weight (per kg) & 4.3 & 1.0 to 7.5 & $<0.05$ & 2.8 & 1.4 to 4.1 & $<0.01$ \\
\hline Birth length (per cm) & 0.96 & 0.17 to 1.74 & $<0.05$ & 0.73 & 0.40 to 1.06 & $<0.01$ \\
\hline
\end{tabular}

Beta is the slope of the linear regression line. $\mathrm{Cl}$ indicates confidence interval

weight and birth length were positively associated with differences in final height in both dizygotic twins (regression coefficient: $3.4 \mathrm{~cm} / \mathrm{kg}$ [ $95-\%$ confidence interval:- 0.32 to $7.1]$ and $0.41 \mathrm{~cm} / \mathrm{cm}$ [-0.63 to 1.45$]$, respectively) and monozygotic twins $(2.1 \mathrm{~cm} / \mathrm{kg}[0.13$ to 4.2$]$ and 0.25 $\mathrm{cm} / \mathrm{cm}[-0.21$ to 0.70$]$, respectively).

\section{Genetic Model Fitting}

Table 5 summarises the genetic model fitting analyses for birth weight and height and for birth length and height. The full model in Table 5 specifies influences of additive genes (A), common - or shared - environment (C) and unique - or not shared - environment (E) for size at birth and height, and for the covariance between them. Compared to this full model, a model that specifies common environmental influences for size at birth only (model 2) does not show a significant deterioration in fit (for birth weight: $\chi^{2}=$ 4.985, $d f=4, p=0.3$; for birth length: $\chi^{2}=5.476, d f=4, p$ $=0.2$ ) indicating that shared familial factors do not contribute to height later in life. Models 3 and 4, however, both fit the data significantly worse (Model 3: for birth weight, $\chi^{2}=18.012, d f=6, p<0.01$; for birth length, $\chi^{2}=28.927$, $d f=6, p<0.001$, and Model 4: for birth weight $\chi^{2}=$ 28.464, $d f=6, p<0.001$; for birth length $\chi^{2}=27.588, d f$ $=6, p<0.001$ ). In model 3 , the covariance between birth weight and height is due solely to environmental factors and genetic effects do not contribute to the covariance. In model 4, genetic factors are the only source of covariation between the two measures. The fact that these more parsimonious models do not describe the data as well as model 2 indicates that the association between size at birth and height is due both to genetic and unique environmental (i.e. intrauterine) factors.

Table 6 (upper panel) shows the proportion of variance in birth weight, birth size and height explained by additive genetic factors, common environment, unique environment and age for men and women separately. Table 6 (lower panel) shows the proportion of co-variance between size at birth and height in later life explained by genetic and environmental factors. Genetic and environmental covariation can also be expressed as genetic and environmental correlations (see Table 7). These correlations may be conceptualised in a simplified manner as an indication of the extent to which genetic (or environmental) influences for two measures are 'the same' or 'overlap'. These correlations differ from the proportion of phenotypic covariation in that the heritability of each variable is not included in calculations. Even though genetic influences on two variables may be slight, it could be that the influences are identical. This would lead to a high genetic correlation, but a low proportion of phenotypic covariation due to the small individual genetic influences. For example, in males, the genetic correlation between birth weight and height in later life was 0.49 , suggesting that about half of the genetic effects on birth weight and height are the same. The environmental correlation between birth weight and height was 0.45 , indicating that about half of the environmental influences on birth weight and height were the same.

\section{$\overline{\text { Discussion }}$}

In accordance with previous studies in singletons, we found positive associations between size at birth and height in later life in twins. In both dizygotic and monozygotic twin pairs, the twins with the lowest birth weight from each pair had a shorter height in later life compared to their co-twins with the highest birth weight. Furthermore, both dizygotic and monozygotic twins with the shortest birth length from each pair had a shorter height in later life compared to their cotwins with the longest birth length. In addition, significant

Table 5

Genetic Model Fitting for Birth Weight and Height and for Birth Length and Height

\begin{tabular}{lcccc}
\hline & \multicolumn{2}{c}{ Birth weight } & \multicolumn{2}{c}{ Birth length } \\
Model & -2log-likelihood & $d f$ & -2 log-likelihood & $d f$ \\
\hline 1. full model (ACE) & 2989.476 & 750 & 3829.144 & 710 \\
2. only C for size at birth & 2994.461 & 754 & 3834.611 & 714 \\
3. no genetic correlation & 3017.940 & 756 & 3858.071 & 716 \\
4. no environmental correlation & 3007.488 & 756 & 3856.732 & 716 \\
\hline
\end{tabular}

Note: The full ACE model included Additive genetic, Common environmental and unique Environmental influences. Model 2 included only $\mathrm{C}$ for size at birth and models 3 and 4 specified no genetic or no environmental association between size at birth and height. All models also included Age as a factor that could explain part of the variance. 


\section{Table 6}

Standardized Parameter Estimates for Size at Birth and Height in Later Life. Proportions of (Co-) Variance Explained by Genetic and Environmental Influences and Age

\begin{tabular}{|c|c|c|c|c|c|c|c|c|}
\hline & \multicolumn{2}{|c|}{ Additive genetic factors } & \multicolumn{2}{|c|}{ Common environment } & \multicolumn{2}{|c|}{ Unique environment } & \multicolumn{2}{|c|}{ Age } \\
\hline & Men & Women & Men & Women & Men & Women & Men & Women \\
\hline \multicolumn{9}{|l|}{ Variables } \\
\hline BW & 0.25 & 0.49 & 0.49 & 0.24 & 0.24 & 0.20 & 0.01 & 0.06 \\
\hline $\mathrm{BL}$ & 0.26 & 0.35 & 0.60 & 0.49 & 0.13 & 0.07 & 0.01 & 0.10 \\
\hline Height & 0.96 & 0.52 & 0.00 & 0.00 & 0.03 & 0.02 & 0.01 & 0.45 \\
\hline \multicolumn{9}{|l|}{ Associations } \\
\hline BW - height & 0.83 & 0.56 & 0.00 & 0.00 & 0.14 & 0.06 & 0.03 & 0.38 \\
\hline $\mathrm{BL}$ — height & 0.81 & 0.51 & 0.00 & 0.00 & 0.16 & 0.03 & 0.03 & 0.46 \\
\hline
\end{tabular}

Note: BW indicates birth weight; BL, birth length.

Table 7

Genetic and Environmental Correlation Between Size at Birth and Height in Later Life

\begin{tabular}{|c|c|c|c|c|}
\hline & \multicolumn{2}{|c|}{$\begin{array}{c}\text { Genetic } \\
\text { correlation }\end{array}$} & \multicolumn{2}{|c|}{$\begin{array}{l}\text { Environmental } \\
\text { correlation }\end{array}$} \\
\hline & Men & Women & Men & Women \\
\hline BW-height & 0.49 & 0.49 & 0.45 & 0.39 \\
\hline BL-height & 0.46 & 0.55 & 0.68 & 0.33 \\
\hline
\end{tabular}

Note: BW indicates birth weight; $\mathrm{BL}$, birth length.

positive associations of intra-pair differences in birth weight and length with intra-pair differences in height were observed in both dizygotic and monozygotic twin pairs. These data suggest that the association between size at birth and height in later life is independent of socio-economic factors and, to some extent, of genetic factors. Intra-uterine factors are therefore likely to be important. However, the comparison of monozygotic twins with dizygotic twins demonstrates that elimination of genetic factors diminishes the size of the association between size at birth and height in later life, suggesting that genetic factors also play a role. This is supported by the genetic model fitting that indicates that models incorporating a genetic source of the variance gave a more accurate description of the association between size at birth and height in later life than models not incorporating a genetic source. Taken together, these data suggest that the association between size at birth and height in later life is influenced by intra-uterine and genetic factors, whereas socio-economic factors do not play a role. Our findings during follow-up suggest that these influences persist into adulthood and are important in the determination of adult height.

Our results in monozygotic twins are consistent with a study that showed a positive association between intra-pair differences in birth weight and adult height in a group of adult monozygotic twins (Allison et al., 1995). However, this study did not examine intra-pair associations in dizygotic twins and therefore, the importance of socio-economic and genetic influences on the association between birth weight and height could not be investigated. Furthermore, data on birth length were not available.

It has been suggested that improvement of fetal nutrition and thus, intra-uterine growth may prevent the development of short stature in later life (Barker, 1998). Our twin study indeed demonstrated that intra-uterine factors play a role in the association between size at birth and height in later life, suggesting that improvement of intra-uterine growth may increase height in later life. This is in accordance with a study in East Java that showed that energy supplementation during pregnancy promoted postnatal growth in children (Kusin et al., 1992), but in contrast to studies in Europe that demonstrated that human exposure to famine in utero did not result in a decreased height in later life (Stanner et al., 1997; Ravelli et al., 1998). It should, however, be noted that the demonstrated associations between intrapair differences in size at birth and differences in height can not be due to maternal nutrition, which is the same for both twins. In addition, the genetic model that specifies common environmental influences for size at birth only did not show a significant deterioration in fit, indicating that shared familial factors (including maternal nutrition) do not contribute to the association between size at birth and height. Therefore, maternal nutrition is not important in the association between size at birth and height in later life. The intrauterine influences on this association may be related to differences in delivery of nutrients to the twins.

Recently, several studies have reported that exogenous growth hormone administration is an effective option to normalise the childhood growth of low birth weight children (Boguszewski et al., 1998; de Zegher et al., 2000; Sas et al., 1999). However, it is unknown whether growth hormone induced a catch-up in growth towards the genetic target level or an acceleration of growth on top of a genetically determined short height. Our results suggest that the association between low birth weight and short height in later life is in part due to intra-uterine factors. Therefore, exogenous growth hormone may influence childhood growth by inducing a catch-up in growth towards the genetic target level.

We conclude that both non-genetic intra-uterine and genetic factors influence the association between size at birth and height in later life. This suggests that improvement of 
the intra-uterine delivery of nutrients may in part prevent the development of short stature in later life.

\section{References}

Albertsson-Wikland, K., Wennergren, G., Wennergren, M., Vilbergsson, G., \& Rosberg, S. (1993). Longitudinal follow-up of growth in children born small for gestational age. Acta Paediatirica, 82, 438-443.

Allison, D. B., Paultre, F., Heymsfield, S. B., \& Pi-Sunyer, F. X. (1995). Is the intra-uterine period really a critical period for the development of adiposity? International Journal of Obesity and Related Metabolic Disorders, 19, 397-402.

Bacallao, J., Amador, M., \& Hermelo, M. (1996). The relationship of birthweight with height at 14 and with the growing process. Nutrition, 12, 250-254.

Barker, D. J., Ed. (1998). Mothers, babies and health in later life. Sidcup, Kent: Churchill Livingstone.

Bavdekar, A., Yajnik, C. S., Fall, C. H., Bapat, S., Pandit, A. N., Deshpande, V., Bhave, S., Kellingray, S. D., \& Joglekar, C. (1999). Insulin resistance syndrome in 8-year-old Indian children: Small at birth, big at 8 years, or both? Diabetes, $48,2422-2429$.

Boguszewski, M., Albertsson-Wikland, K., Aronsson, S., Gustafsson, J., Hagenas, L., Westgren, U., Westphal, O., Lipsanen-Nyman, M., Sipila, I., Gellert, P., Muller, J., \& Madsen, B. (1998). Growth hormone treatment of short children born small-for-gestational-age: The Nordic multicentre trial. Acta Paediatrica, 87, 257-263.

Boomsma, D. I., Hennis, B. C., van Wees, A. G., Frants, R. R., \& Kluft, C. (1993). A parent-twin study of plasma levels of histidine-rich glycoprotein (HRG). Thrombosis and Haemostasis, 70, 848-851.

Boomsma, D. I., Kaptein, A., Kempen, H. J., Gevers, L. J., \& Princen, H. M. (1993). Lipoprotein(a): Relation to other risk factors and genetic heritability. Results from a Dutch parenttwin study. Atherosclerosis, 99, 23-33.

Boomsma, D. I., Snieder, H., de Geus, E. J., \& van Doornen, L. J. (1998). Heritability of blood pressure increases during mental stress. Twin Research, 1, 15-24.

Bring, J., \& Wernroth, L. (1999). Inefficient analysis of twin data: Is there an association between diabetes and birth weight? Diabetologia, 42, 898-899.

Cheung, Y. F., Taylor, M. J., Fisk, N. M., Redington, A. N., \& Gardiner, H. M. (2000). Fetal origins of reduced arterial distensibility in the donor twin in twin-twin transfusion syndrome. Lancet, 355, 1157-1158.

de Zegher, F., Albertsson-Wikland, K., Wollmann, H. A., Chatelain, P., Chaussain, J. L., Lofstrom, A., Jonsson, B., \& Rosenfeld, R. G. (2000). Growth hormone treatment of short children born small for gestational age: Growth responses with continuous and discontinuous regimens over 6 years. Journal of Clinical Endocrinology and Metabolism, 85, 2816-2821.

Delpeuch, F., Traissac, P., Martin-Prevel, Y., Massamba, J. P., \& Maire, B. (2000). Economic crisis and malnutrition: Socioeconomic determinants of anthropometric status of preschool children and their mothers in an African urban area. Public Health Nutrition, 3, 39-47.

Hadders-Algra, M., \& Touwen, B. C. (1990). Body measurements, neurological and behavioural development in six-year- old children born preterm and/or small-for-gestational-age. Early Human Development, 22, 1-13.

Ibanez, L., Potau, N., Enriquez, G., \& de Zegher, F. (2000). Reduced uterine and ovarian size in adolescent girls born small for gestational age. Pediatric Research, 47, 575-577.

Ijzerman, R. G., Stehouwer, C. D., \& Boomsma, D. I. (2000). Evidence for genetic factors explaining the birth weight-blood pressure relation: Analysis in twins. Hypertension, 36, 1008-1012.

Karlberg, J., \& Albertsson-Wikland, K. (1995). Growth in fullterm small-for-gestational-age infants: From birth to final height. Pediatric Research, 38, 733-739.

Karlberg, J., \& Luo, Z. C. (2000). Foetal size to final height. Acta Paediatrica, 89, 632-636.

Kusin, J. A., Kardjati, S., Houtkooper, J. M., \& Renqvist, U. H. (1992). Energy supplementation during pregnancy and postnatal growth. Lancet, 340, 623-626.

Leger, J., Levy-Marchal, C., Bloch, J., Pinet, A., Chevenne, D., Porquet, D., Collin, D., \& Czernichow, P. (1997). Reduced final height and indications for insulin resistance in 20 year olds born small for gestational age: Regional cohort study. British Medical Journal, 315, 341-347.

Leger, J., Limoni, C., Collin, D., \& Czernichow, P. (1998). Prediction factors in the determination of final height in subjects born small for gestational age. Pediatric Research, 43, 808-812.

Neale, M. C. (1995). Mx: Statistical modeling ( $2^{\text {nd }}$ ed.). Richmond, VA: Department of Psychiatry.

Nilsen, S. T., Finne, P. H., Bergsjo, P., \& Stamnes, O. (1984). Males with low birthweight examined at 18 years of age. Acta Paediatrica Scandinavica, 73, 168-175.

Paz, I., Seidman, D. S., Danon, Y. L., Laor, A., Stevenson, D. K., \& Gale, R. (1993). Are children born small for gestational age at increased risk of short stature? American Journal of Diseases of Children, 147, 337-339.

Phillips, D. I. (1993). Twin studies in medical research: Can they tell us whether diseases are genetically determined? Lancet, 341, 1008-1009.

Poulsen, P., Vaag, A. A., Kyvik, K. O., Moller, J. D., \& BeckNielsen, H. (1997) Low birth weight is associated with NIDDM in discordant monozygotic and dizygotic twin pairs. Diabetologia, 40, 439-446.

Poulter, N. R., Chang, C. L., MacGregor, A. J., Snieder, H., \& Spector, T. D. (1999). Association between birth weight and adult blood pressure in twins: Historical cohort study. British Medical Journal, 319, 1330-1333.

Rantakallio, P., \& von Wendt, L. (1985). Prognosis for low-birthweight infants up to the age of 14: A population study. Developmental Medicine and Child Neurology, 27, 655-663.

Ravelli, A. C., van der Meulen, J. H., Michels, R. P., Osmond, C., Barker, D. J., Hales, C. N., \& Bleker, O. P. (1998). Glucose tolerance in adults after prenatal exposure to famine. Lancet, $351,173-177$.

Sas, T., de Waal, W., Mulder, P., Houdijk, M., Jansen, M., Reeser, M., \& Hokken-Koelega, A. (1999). Growth hormone treatment in children with short stature born small for gestational age: 5-year results of a randomized, double-blind, doseresponse trial. Journal of Clinical Endocrinology and Metabolism, 84, 3064-3070. 
Sorensen, H. T., Sabroe, S., Rothman, K. J., Gillman, M., Steffensen, F. H., Fischer, P., \& Sorensen, T. I. (1999). Birth weight and length as predictors for adult height. American Journal of Epidemiology, 149, 726-729.

Stanner, S. A., Bulmer, K., Andres, C., Lantseva, O. E., Borodina, V., Poteen, V. V., \& Yudkin, J. S. (1997). Does malnutrition in utero determine diabetes and coronary heart disease in adulthood? Results from the Leningrad siege study, a cross sectional study. British Medical Journal, 315, 1342-1348.

Treloar, S. A., Sadrzadeh, S., Do, K. A., Martin, N. G., \& Lambalk, C. B. (2000). Birth weight and age at menopause in Australian female twin pairs: Exploration of the fetal origin hypothesis. Human Reproduction, 15, 55-59.

Tuvemo, T., Cnattingius, S., \& Jonsson, B. (1999). Prediction of male adult stature using anthropometric data at birth: A nationwide population-based study. Pediatric Research, 46, 491-495.

Westwood, M., Kramer, M. S., Munz, D., Lovett, J. M., \& Watters, G. V. (1983). Growth and development of full-term nonasphyxiated small-for- gestational-age newborns: Followup through adolescence. Pediatrics, 71, 376-382. 